\title{
Unintended Use Error Caused or Contributed to Event
}

National Cancer Institute

\section{Source}

National Cancer Institute. Unintended Use Error Caused or Contributed to Event. NCI Thesaurus. Code C91895.

The interaction between the user and device, or sample, caused or contributed to the error. This includes unintended inappropriate use of the device and incorrect sample preparation. 